\title{
8 Approach of Customer Relationship Management as a Managerial Synapse
}

\section{Short Customer Relationship Management (CRM) Genesis and Development (Evolution)}

Thousands of years ago people started to trade, first using bartering and later money. The first recorded commercial activity was about 20,000 years ago. Quite quickly traders realized that it is easier to sell to previous customers than to find new ones and that it is advantageous to develop as good relationships as possible with them. Gradually an accounting registration system was developed incorporating information regarding the buyer's name and location, product type and quantity sold, price, etc. This information regarding customers recorded in accounting documents represents an early type of customer database. Such information was used in the first segmentation of customers taking into consideration customers' payment capacity, buying frequency, etc. We can state that the action of recording and grouping customers has a relatively long history and this represents the main reason for the many traders' performant business.

In the twentieth century, because of the keen concurrence in all fields, the attraction, retaining, and loyalization of customers became more and more important for company survival and development. From the old codes, agendas and the famous rolodex used by many companies for customer centralization and coordination in the 70s, with the development of informatics, CRM specialized software was designed and used.

The first CRM programs emerged in the United States between 1970 and 1980, when stand-alone mainframe systems were introduced, containing information regarding sales to customers. These systems provided sales department staff with the tools required for obtaining data regarding customer management. Between 1981 and 1990 North American insurance and finance companies began to use certain software specially designed for them that was able to connect information about customers and trade transactions used in the company business. In 1982, a marketing database was introduced aimed at using some statistical methods for collecting and analysing customer data. In 1986, the first 
software for the administration of sale contracts, called ACT, was launched. In the 1990s, as a consequence of the change in business paradigm and of the software focused on customers, the CRM concept was developed and disseminated rapidly.

Significant contributions to the change of business paradigm were made by Kotler (1992a, 1992b) regarding the transition from transactional marketing to relational marketing; Hammer and Champy (1993), who highlighted the need for customer-centric business models; and Peppers and Rogers (1993), through their introduction of the concept of "one-to-one marketing".

In this context, new approaches to organization performance based on the "relationship concept" were elaborated that contributed to other major changes in the marketing field and orientation toward the customer. Kotler emphasized the importance of developing closer relationships with customers, distributors, suppliers, company managers and employees, trade unions, banks, NGOs, governmental bodies, and other major players (stakeholders) in the company business environment. The need for a transition from short-term vision, oriented towards transactions, to a long-term approach, centred on the creation and development of relationships, whose goal is organization competitivity, and enhancement of the local, regional, national, and international markets, has been stressed. The transition from transactional marketing to relational marketing has been achieved based on two major mutations (Bălan, 2007):

- the transition from a narrow perspective focused only on the functional area to a vision centred on the correlative approach of several functional areas;

- the objective of attracting customers has proved insufficient for sustainable development and, as result, has led to the transition to a double objective centred on taking into consideration stakeholders' categories (not only customers) and on maintaining customers. It should be noted that various specialists (e.g., Parvatiyar \& Sheth, 2001b) believed that the terms "relationship marketing" and CRM were frequently used interchangeably in the academic world.

At the beginning of the 1990s, in the context of the rapid development of informatics, an important step was made toward the development of software that would later be known as CRM. Brock Control Systems and Siebel Systems contributed significantly to the evolution of software for contracts management to sales force automation (SFA), which has automated many of the main elements of database marketing and combined them with contracts management, providing companies 
with very useful information about customers. Over time, SFA and other software for contracts management have had different names, like CRM (Customer Relationship Management), ECM (Enterprise Customer Management), and CIS (Customer Information System). In 1995, the term CRM was definitively accepted in the USA and at international level. Later some companies, such as Oracle and SAP, started to incorporate CRM modules in enterprise resource planning (ERP) software that were initially dedicated to business activities like product planning, manufacturing, transportation, etc. In 1999, the first mobile CRM, with the name Siebel Sales Handheld, was launched, followed by versions made by other top companies like PeopleSoft, SAP, and Oracle. Salesforce.com implemented the first software cloud SaaS CRM (Software-as-a-Service) ("CRM", n.d.). Between 2000 and 2010, Microsoft entered the CRM market with Dynamics CRM, and SugarCRM developed the first open-source CRM. Cloud-based CRM became dominant and social media was integrated into CRM. After 2010, the most important developments were: CRM integrations with business intelligence services and communication systems, enhancement of CRM customization capabilities based on the activity domain, line of business, sales process or market focus, the appearance of visual, highly intuitive CRM such as Pipedrive, improvements in mobile access, and increased use of $\mathrm{AI}$ and machine learning for various purposes (Gaetano, 2018). In summary, the evolution of CRM software can be divided into four main periods or stages: the 1980s or the original stage, the 1990s or the expansion stage, the 2000s or the modern CRM stage, and the last stage, from 2010 to the present, dominated by Cloud-Social-Mobile-Integrated CRM software (Khasenova, 2017). CRM operationalization in companies has developed in a very innovative and successful way both in terms of reconfiguration of the activities within organizations according to a new conception centred on the customer and from the point of view of the use of information and communication technologies. Some specialists refer to customer relationship management as an integrated approach to identifying, acquiring and retaining customers, when the focus of CRM is on managerial elements (Ellatif, 2008), and others see CRM as informatics tools/systems designed to support the relationships between company and customers (Chen \& Popovich, 2003). The strategy of a company that focuses on the clients and the CRM software complement each other. But CRM technology is often incorrectly equated with CRM (Reinartz, Krafft, \& Hoyer, 2004), and one of the main reasons for the failure of CRM in many organizations is approaching CRM as a technology initiative (Kale, 2004). For this reason, there must be a balance between the integrated approaches of a strategic nature and the use of the elements provided by the ITC industry. 


\section{CRM Definition and Mechanism}

Surprisingly, there is no definition of CRM widely accepted at the international level. Although the term CRM is very frequently used and in many companies CRM systems are implemented as software applications or fuller approaches that deal with many company activities, the perceptions of scientists and practitioners regarding CRM vary greatly. Some specialists believe that the best CRM approach derives from the aphorism "the purpose of business is to create and to keep a customer", formulated by Peter Drucker a long time ago (Drucker, 1954).

Starting from the approach levels, the errors regarding the understanding of the concept, the different points of view regarding the content and the contexts of implementation, Francis Buttle identified a number of essential attributes of CRM, which he integrated into the following definition: "CRM is the core business strategy that integrates internal processes and functions, and external networks, to create and deliver value to targeted customers at a profit. It is grounded on highquality customer data and enabled by IT" (Buttle, 2004, p. 34).

The well-known global research and consulting firm Gartner defined CRM as

a business strategy that optimizes revenue and profitability while promoting customer satisfaction and loyalty. CRM technologies enable strategy, and identify and manage customer relationships, in person or virtually. CRM software provides functionality to companies in four segments: sales, marketing, customer service and digital commerce. ("Gartner Glossary”, n.d.)

A very interesting approach to the definition of CRM was taken by Payne and Frow (2005), who believed that customer relationship management can be defined from at least three perspectives: narrowly and tactically, broadly and tactically, broadly and strategically. Payne and Frow, after a comprehensive review of the specialized literature and intense interaction with managers from many and various companies, formulated a more complex CRM definition:

CRM is a strategic approach that is concerned with creating improved shareholder value through the development of appropriate relationships with key customers and customer segments. CRM unites the potential of relationship marketing strategies and IT to create profitable, long-term relationships with customers and other key stakeholders. CRM provides enhanced opportunities to use data and information to both understand customers and co-create value with them. This requires a cross-functional integration of processes, people, operations and marketing capabilities that is enabled 
through information, technology and applications. (Payne \& Frow, 2005, p. 168)

We shall continue by presenting certain CRM definitions very frequently quoted in the specialized literature: "CRM attempts to provide a strategic bridge between information technology and marketing strategies aimed at building long-term relationships and profitability. This requires information-intensive strategies" (Glazer, 1997). "CRM is a management approach that enables organizations to identify, attract and increase the retention of profitable customers by managing relationships with them" (Hobby, 1999). "CRM means being willing and able to change your behaviour toward an individual customer based on what the customer tells you and what else you know about that customer" (Peppers, Rogers, \& Dorf, 1993, p. 151). "CRM involves using existing customer information to improve company profitability and customer service" (Couldwell, 1999, p. 14). "CRM is nothing more than an approach that stems from the need to create a new business environment, which allows a more effective management of relationships with customers" (Galbreath \& Rogers, 1999). "CRM is an enterprise approach to understanding and influencing customer behaviour through meaningful communication to improve customer acquisition, customer retention, customer loyalty and customer profitability" (Swift, 2000). "CRM is a comprehensive strategy and process of acquiring, retaining and partnering with selective customers to create superior value for the company and the customer" (Parvatiyar \& Sheth, 2001b). "CRM is a term for methodologies, technologies and e-commerce capabilities used by companies to manage customer relationships" (Stone \& Woodcock, 2001). "CRM is a set of methodologies, processes, software and systems that helps institutions and companies in creating effective and organized management of customer relationships" (Burnett, 2001). "CRM is an ongoing process of identifying and creating new value with individual customers, and then sharing the benefits from this value over a lifetime. It involves the understanding and focused management of ongoing collaboration between an organization and its selected customers for mutual value creation and then sharing this value through interdependence and organizational alignment" (Brunjes \& Roderick, 2002, p. 9). "CRM is the infrastructure that enables the delineation of an increase in customer value, and the correct means by which to motivate valuable customers to remain loyal - indeed, to buy again" (Dyché, 2002, p. 4). "CRM is not merely technology applications for marketing, sales and service, but rather, when fully and successfully implemented, a cross-functional, customer-driven, technology-integrated business process management strategy that maximizes relationships and encompasses the entire organization" (Chen \& Popovich, 2003, p. 673). "CRM is a business strategy to select and manage customers to optimize long-term value. CRM 
requires a customer-centric business philosophy and culture to support effective marketing, sales and service processes. CRM applications can enable effective customer relationship management, provided that an enterprise has the right leadership, strategy and culture" (Subhasish, 2007 , p. 4). "CRM is a comprehensive sales and marketing approach to building long-term customer relationship management and improving business performance" (Farooqi \& Dhusia, 2011).

Various specialists from around the world have identified several CRM levels, CRM types or perspectives on CRM strategic, operational, and analytical (e.g., Bălan, 2007; Reiny \& Buttle, 2006); operational, analytical, and collaborative (e.g., Karimi, Somers, \& Gupta, 2001; Payne, 2005; Tohidi \& Jabbari, 2012); functional, customer facing and organizational or strategic (e.g., Kumar \& Reinartz, 2018).

According to Buttle (2009), there are four types of CRM: strategic, operational, analytical, and collaborative (see Figure 8.1).

1 Strategic, which refers to CRM positioning as a major component of the overall organization strategy. Management of the customer relationships involves the development of an organizational culture centred on the customers and the use of customer orientation as a priority at the level of the entire company. Customer acquisition and increase of the customers' degree of satisfaction should not be left only to the marketing and/or sales department. Promises to customers can only be fulfilled continuously and entirely through horizontal integration of all company activities and through orienting organization resources and processes to the satisfaction of the customers' expectations. In each business entity, it is necessary to align and integrate the customer strategy with the company's overall strategy. If there is a gap between strategies, there will be a negative impact on the organization because of the discrepancy between the value provided to the customers and their expectations.

2 Operational, which refers to the automation of the company's contact activities with the customers. Automation projects deal with marketing, sales, service and activities using CRM software applications. Marketing automation deals with the following processes: customer segmentation, communication campaigns management and answering customers. Sales force automation refers to opportunities management, contact management, offers management, and the establishment of customer solutions. Service automation deals mainly with operations between customer contact centres and telemarketing centres, services provided by the Internet and partners' activities.

3 Analytical, which refers mainly to data mining regarding the customers and evaluation of the organization's performances in the field of customer relationships, in order to elaborate the best 


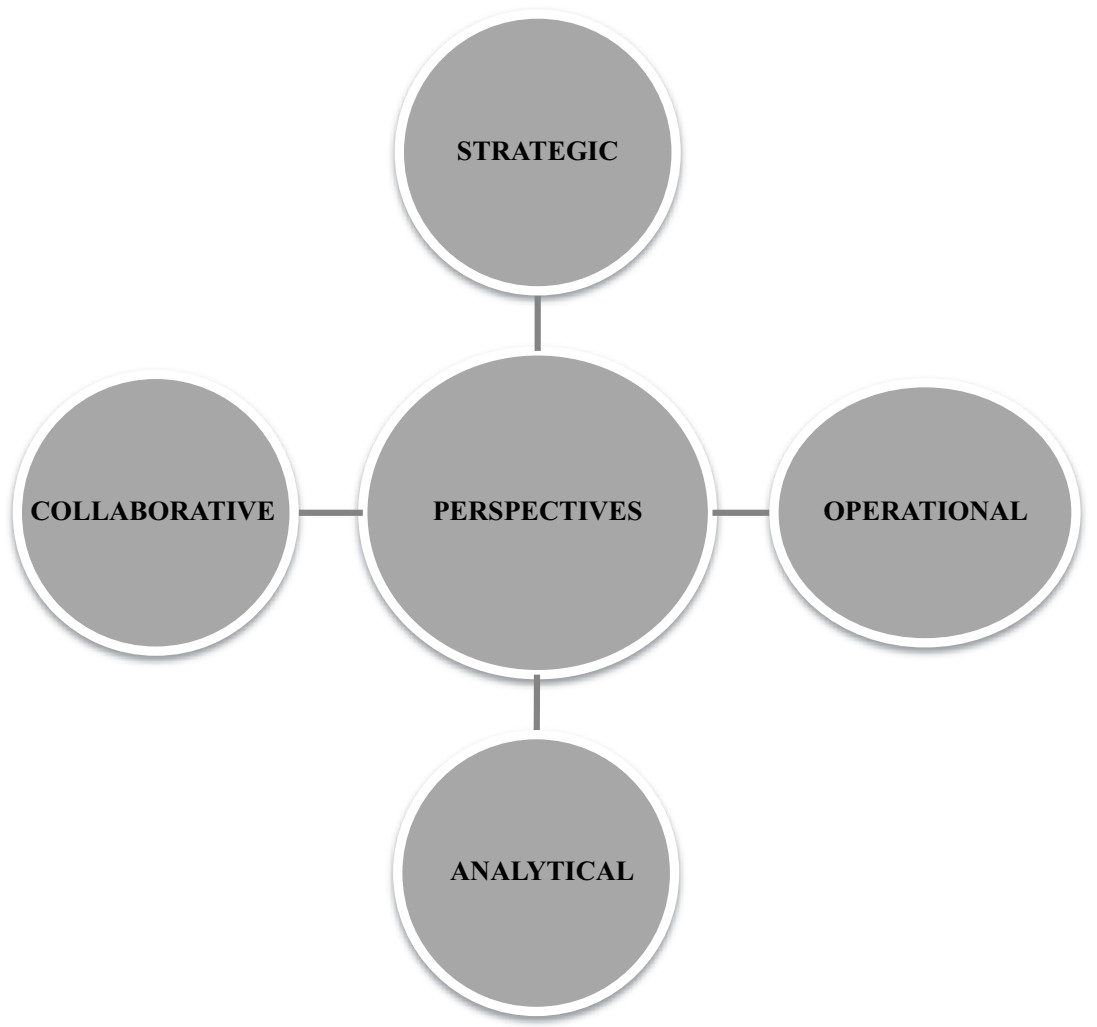

Figure 8.1 Major perspectives on customer relationship management.

Adapted from Customer relationship management: Concepts and technologies (p. 4), by F. A. Buttle, 2009, Elsevier Butterworth-Heinemann. Retrieved from https://knowledgestreams. files.wordpress.com/2013/07/francis_buttle-customer_relationship_management_second_ edition-butterworth-heinemann2008_2.pdf

strategies, policies, and tactics for each major customer. The analytical level includes processes of information gathering, analysis, interpretation, use, and storage regarding the customers, the most important of which are the following: customer identification, profiling customers from the company portfolio, data analysis, and evaluation of the marketing processes.

4 A collaborative approach to CRM refers both to the organization's cooperation with external stakeholders (suppliers, vendors, and distributors) resulting in better alignment in the supply chain of separate enterprises in order to identify, attract, and retain the customers in a performant manner (Buttle, 2009), and also to the internal communications between different departments of an organization (sales, marketing, and technical support) to improve 
the quality of customer service and enhance customer satisfaction/ loyalty (Jha, 2008). According to Payne (2005, p. 23), "collaborative CRM involves the use of collaborative services and infrastructure to make interaction between a company and its multiple channels possible. This enables interaction between customers, the enterprise and its employees".

In order to achieve the objectives of CRM regarding value creation both for the company and for the customer, four CRM levels/types should be automated - strategic, operational, analytic, and collaborative.

The development of the Internet and the popularity of social media have generated the emergence of electronic CRM (E-CRM) and social CRM (S-CRM).

Coined in the mid-90s, E-CRM has been defined in many ways by diverse specialists. For instance: "Electronic Customer Relationship Management is the use of ICT tools by organizations as a means of building potentially long-lasting relationships with customers" (Kotorov, 2002); "E-CRM refers to the use of the Internet to implement CRM strategies" (Blery \& Michalakopoulos, 2006); "E-CRM is actually CRM on the web and involves e-commerce activity and use of email and other Internet-based touch points" (Bergeron, 2004); "Electronic CRM is simply CRM that includes the use of technology" (Harrigan, Ramsey, \& Ibbotson, 2012).

Social CRM, which focuses on the use of social media to support and develop the interactions between the organization and customers, has been defined differently by different scholars: "Social CRM is an emerging concept that includes strategies, processes and technologies to link the Social Web with CRM processes" (Reinhold \& Alt, 2011); "S-CRM is CRM strategy that encourages customer collaboration and involvement" (Faase, Helms, \& Spruit, 2011); "Social CRM is emerging as a new paradigm for integrating social networking in more traditional CRM systems" (Askool \& Nakata, 2011); other specialists believed that S-CRM consists in CRM systems that make use of blogs, forums and other social media to broaden the focus of traditional CRM (e.g., Gneiser, 2010; Trainor, Andzulis, Rapp, \& Agnihotri, 2014), but the most widely accepted approach belongs to Greenberg $(2009$, p. 34) who defined social CRM as:

[a] philosophy and a business strategy, supported by a technology platform, business rules, workflow, processes and social characteristics, designed to engage the customer in a collaborative conversation in order to provide mutually beneficial value in a trusted and transparent business environment. It's the company's programmatic response to the customer's control of the conversation. 
CRM consolidation as a management approach was influenced by the major trends that have manifested worldwide since the 1990s (Payne, 2005): transition from transactional marketing to relational-based marketing; awareness to a greater extent of the fact that clients are a business asset; reconfiguration in structuring organizations by moving the accent from functions to processes; increased use of ICT technologies in managing and exploiting the value of information; admission of the need for trade-off between delivering and appropriating customer value; proliferation of one-to-one marketing approaches; and recognition of the advantages of using information proactively than rather in a reactive way.

\section{Main Approaches of CRM in the Specialized Literature and Company Practice}

At the international level there are many CRM approaches conducted by scientists and by company specialists, but the objectives and essential elements are, to a large extent, similar. The different approaches are caused mainly by rapid societal changes, which gradually determine updates of CRM systems, the existence of many companies from different branches where CRM is implemented, and the specificity of personal training and experience of the specialists who deal with CRM. We shall briefly present some of the CRM approaches that require special attention from the specialists.

The IDIC model, one of the best-known CRM approaches, was elaborated by the consultancy company Peppers \& Rogers Group, and has been featured in several books written by the two consultants (e.g., Peppers \& Rogers, 1996, 2004). The model focuses on four actions that the company has to undertake in order to build and develop long-term one-to-one relationships with customers:

- Identify the customers of the organization and collect as much information or data about them as possible in order to enhance the understanding of their needs and purchase behaviours;

- Differentiate the customers on the basis of value (identification of customers that have the most value now or in the future) and according to their needs (serving various customers that have different needs in profitable ways requires more knowledge about their needs);

- Interact with customers in order to understand their expectations and their relationships with a brand;

- Customize the products and services to be certain that the expectations of customers are met.

The specialists Parvatiyar and Sheth (2001a, 2001b) have developed a broad framework for the CRM process, divided into four subprocesses: 


\section{Approach of Customer Relationship}

- Customer relationship formation process. This subprocess refers to setting the purposes of implementing CRM, selecting parties or customer groups for the CRM programme, and developing programmes for relational engagement with the customers;

- Relationship management and governance process approaches issues like team structure, role specification, process alignment, communication, motivation of specialists, and employee training;

- Relationship performance evaluation process. This is focused on the measurement of the CRM process and comparison with the initial objectives, defined at the start of CRM implementation. The main areas to be assessed are strategic, financial, and marketing issues;

- CRM enhancement process refers to the evolutionary process that can occur naturally according to developments occurring in the external environment, and/or based on the experiences accumulated during the implementation of CRM.

Based on many years' theoretical and practical research, renowned professor Francis Buttle elaborated the CRM value chain (Buttle, 2001, 2004, 2009), which is one of the best-known CRM models in the world, dedicated to companies that want to develop and implement CRM strategies. Buttle's model focused on five primary stages and four supporting conditions that lead to the achievement of the main goal of any company customer profitability enhancement. The primary stages, respectively customer portfolio analysis, customer intimacy, network development, value proposition development and managing the customer life cycle, are approached in a sequential manner in order to ensure that an organization, supported by its network of partners, suppliers, and employees, is able to acquire and retain profitable customers. The main supporting conditions are leadership and culture, information technology, people, and processes, which make the successfully implementation of the CRM strategy possible.

One of the most popular approaches to CRM worldwide was formulated by Payne (2005), who concluded that most companies should take into consideration five key cross-functional CRM processes: strategy development process, value creation process, multi-channel integration process, information management process, and performance assessment process (see Figure 8.2).

Based on these cross-functional CRM processes, Payne and Frow (2005) elaborated the strategic framework for customer relationship management. According to this approach, CRM is regarded as a strategic set of processes that starts with a detailed review of an organization's strategy (process of strategy elaboration) and ends with an improvement of business results and increase of shareholder value (process of performance assessment). A company's competitive advantage results from the creation of value for the customer and for the 


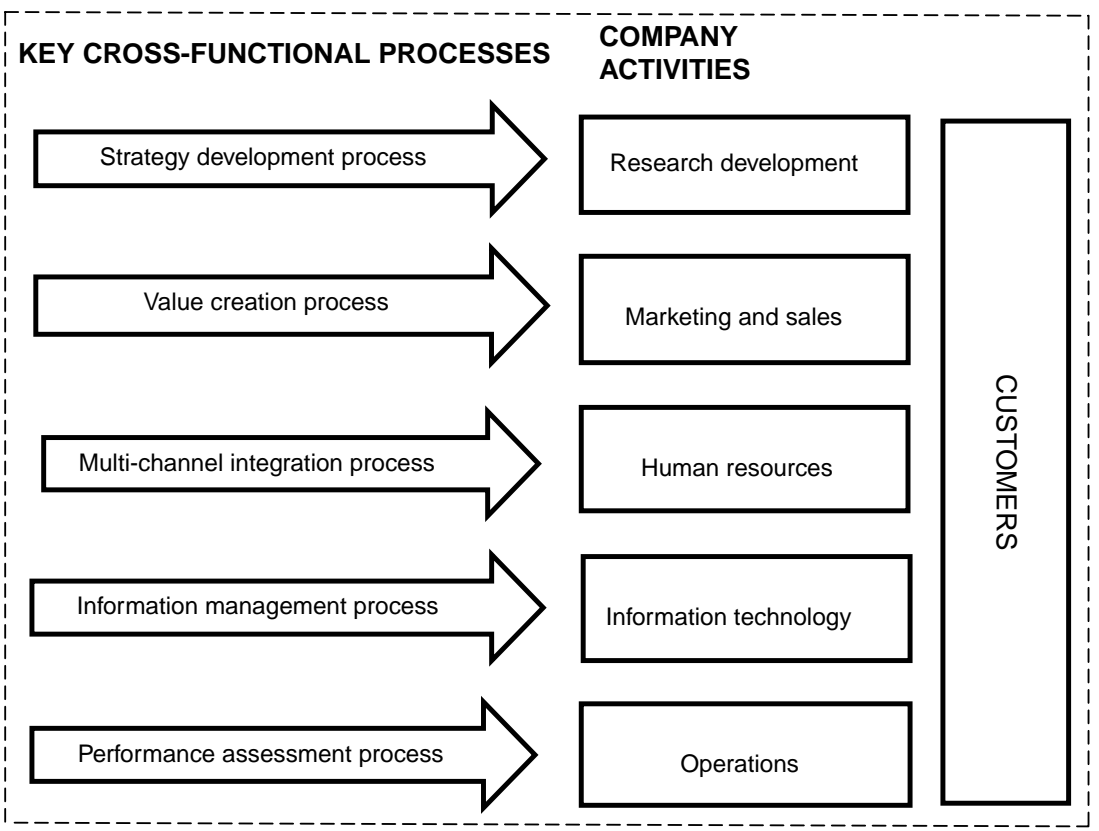

Figure 8.2 CRM as a cross-functional activity - Levels of customer relationship management.

Adapted from Handbook of CRM: Achieving excellence in customer management (p. 30) by A. Payne, 2005, Butterworth-Heinemann and Elsevier. Retrieved from https://repository.dinus.ac.id/docs/ajar/Handbook_of_CRM.pdf

organization (process of value creation) through collecting and utilizing in an intelligent manner customer and other relevant data (information management process) in order to build a superior customer experience, at each touchpoint where an interaction between customer and supplier (multi-channel integration process) exists.

With regard to the model elaborated by Payne and Frow, specialist Buttle (2009) mentioned that the strategy development process and the value creation process represent strategic CRM, the multichannel integration process constitutes operational CRM and the information management process signifies analytical CRM.

A very interesting approach is that of Santos and Castelo (2018), who presented a conceptual model for the adoption of CRM in terms of a strategic perspective. This approach was developed based on the analysis of over 30 models elaborated between 1999 and 2015 and is focused on elements internal to the organization that are grouped in six dimensions:

- CRM strategy formulation;

- Relational marketing philosophy; 


\section{Approach of Customer Relationship}

- The application of best practices;

- Organizational and human resources;

- CRM processes;

- CRM technology.

The first two dimensions are related to the design of a CRM strategy and the next four dimensions are approached in terms of implementation. The proposed model includes three functional areas (marketing, sales, and after-sales services) and stresses the need to consider the permanent application of best practices and management of metrics.

In order to support companies that wish to implement electronic CRM or are in the process of implementing E-CRM, Pan and Lee (2003) elaborated a model focused on five managerial steps:

- Identify the existing customer relationship management processes within the organization. Detailed knowledge of all processes focused on customers is of great importance, because it will provide answers regarding what specific business benefits are sought from the CRM strategy;

- Formulate an E-CRM vision and strategy. In the second step, an E-CRM strategy and its specific objectives must be established and build upon the existing CRM processes;

- Secure top management support. Depending on the organizational and IT culture as well as their own circumstances, the support level of top management plays a crucial role in the E-CRM implementation process;

- Choose appropriate technology partners. An important challenge for organizations implementing E-CRM is choosing the right technology partner, which must be able to offer a flexible, customized, and scalable product and stay focused on the business objectives and the overall E-CRM vision of the organization;

- Evaluate current information systems and create new mechanisms and metrics to monitor and improve the process. The last step is aimed at the assessment of E-CRM implementation and the adoption of corrective and/or improvement measures.

Alt and Reinhold (2019) developed a model focused on social CRM that reveals the design areas of a CRM solution (operational, analytical, communicative, and collaborative), the actors (users, platform provider/providers, companies, and service providers) and the five technological elements (social media, analysis, CRM, interaction, and management/integration). The first element (social media) refers to establishing a presence on a social media platform/platforms (such as forums, wiki, and communities) for the distribution and collaborative generation of information. The second element (analysis) deals with the identification of relevant content, 
main actors and services on the social web, impact analysis of customeroriented activities and interpretation of social web content, supported through analytical technique use (e.g., evaluation, filtering, search, aggregation, enrichment, transformation, etc.). The third element (interaction) comprises functionalities for communication between an organization and social media users, on the basis of interaction technique use (e.g., content delivery, dialogue development, publication, dissemination, recommendation). The fourth element (CRM) refers to functionalities for operational, analytical, communicative, and cooperative CRM activities and for using social content in CRM activities. The fifth element (management/integration) refers to operative and strategic control of social media activities and channels, integration between systems and enhancing capabilities to act on the social web.

Presenting several CRM approaches/models is useful for better understanding the major elements referring to CRM and for the analysis of CRM using the features of the managerial synapse.

\section{CRM Evaluation Using the Features of Managerial Synapse}

Customer relationship management is widely practised throughout the world and, when implemented professionally, generates high performance, regardless of the field of activity and/or size of organizations. In this section, CRM will be evaluated in terms of the defining characteristics of the relationship developed within the managerial synapse: joint interests and objectives, win-win approach, trust capital, reciprocal advantages, reasonable compromise, dialogic communication, loyalty, commitment, collaboration, cooperation, and a new mechanism - value creation stakeholder partnership.

\section{Joint interests and objectives}

The CRM background is always represented by common and/or complementary interests of the organization and the customers involved. These interests usually refer to the type, quality, price, and quantity of the products provided by the company. Sometimes the location, the size and the prestige of the company and of the stakeholders, the business potential, market evolution, and/or other significant elements in the specific context are important. Based on common interests, the organization and the stakeholders negotiate joint objectives, which are incorporated frequently in the contracts. Joint interests and objectives are mandatory in all CRM. In business there are relatively frequent situations when the joint objectives do not reflect the common and/or complementary interests sufficiently. When such a situation occurs, the sustainability of CRM is not ensured and the continuation of the business between the company and its customers is in danger. 


\section{Approach of Customer Relationship}

\section{Win-win approach}

CRM, regardless of the types of programmes (continuity marketing, oneto-one marketing, partnering/co-marketing) and customers (mass markets, distributors, business to business), very frequently focuses on winwin approaches. On the one hand, the companies that sell products/ provide services obtain income as a result of transactions with customers, and on the other hand, the clients - natural or legal individuals gain as a result of the acquisitions, either at the level of psychological satisfaction or from the economic point of view, as a result of carrying out economic activities under the conditions of a convenient ratio between the quality and the price of the purchases. However, not all CRM approaches are based on win-win negotiation; quite frequently some companies or powerful customers do not use win-win negotiation, but "forceful" negotiation, neglecting or not taking into consideration enough the major interests of the other part. There are specialists (e.g., Polonsky \& Wood, 2001) who have referred to situations in which companies implemented CRM tactics that increased corporate returns without corresponding benefits for consumers and society. Also, there are situations in which customers do not generate profit, or enough profit, from sales, altering the win-win approach. In such a situation CRM is not able to generate performant and sustainable business for the company and customers involved.

\section{Trust capital}

Building trust is one of the major areas on which the company needs to focus in order to accomplish strong customer relationships (McKean, 2003; Payne, 2005). Trust is the central element in maintaining and reinforcing the existing relationships and represents the key issue in CRM (Law, Wong, \& Lau, 2005). In aiming to build and develop clients' trust, CRM approaches strive to treat customers honestly and ethically, to respond rapidly to their problems and/or queries. Customers are more drawn to trustworthy partners and the most important outcomes of customers' trust are better cooperation, enhanced commitment and prolonged relationship duration. According to Boulding, Staelin, Ehret, and Johnston (2005), the precursor to trust capital is fairness, and for this reason organizations must be very careful that CRM activities do not cross the line regarding what the customers consider fair. Although CRM approaches have proven to be efficient, with a broadly favourable impact on organizations' activities, situations where customers have perceived themselves as being exploited by a company's CRM schemes are frequently encountered. This is due to the fact that CRM is sometimes overused or misused, and to some marketing tactics that are deceptive or manipulative, based on wrong practices that harm customers and increase distrust (Nguyen, Simkin, \& Canhoto, 2015). Some specialists (e.g., 
Nguyen, 2012) have referred to the potential hidden costs of customer distrust for organizations (disloyalty, negative word of mouth, diminishing of customer lifetime value, reducing of marketing effectiveness, etc.).

\section{Reciprocity/reciprocal advantages}

CRM is a managerial approach based on the reciprocal behaviour of the parties involved, namely the organization that sells/provides services and the entity that buys (individual or legal). Specialists (e.g., Payne, 2005) have emphasized that there must be advantages for both parties for successful CRM. Most companies that implement CRM strategies/approaches/systems view customer relationships, especially long-term and B2B-type relationships, as partnerships oriented toward a constant effort to create added value in the mutual exchange of values between buyer and seller. Reciprocal benefits are economic, social, ecological, psychological, etc. There are organizations in which CRM is mistakenly approached, where the focus is on "what the firm could do, not what the customer would get", eluding to the fact that "if there is no benefit to the customer, there can be no benefit to the company" (Payne, 2005, p. XIV). In CRM, reciprocity has a very important behavioural dimension, with the values, fairest attitudes and behaviours of the people who work being quite often determinant for the continuation and performances of the business. There are numerous situations when behavioural elements have a negative impact on CRM, sometimes even stopping the trade relationships.

\section{Reasonable compromise}

Most of the relationships between organizations and their customers are characterized by mutual concessions, even renunciations, usually within reasonable limits. Thus, on the one hand, CRM schemes incorporate loyalty programmes, bonuses, discounts, deals, staggered payments, personalized products/services tailored to clients' particular needs, etc., and on the other hand, customers are willing to continue buying products/services under conditions of a reasonable price-quality ratio and possibly paying a higher price for the brand, various services, personalization, etc. When there are divergences between the company and the client, it is generally sought to settle them amicably, as litigation in court results in termination of the relationship. Although CRM operationalizes concession-based relationships, many agreements between companies and customers cease due to the impossibility of making reasonable compromises (purchases from an important competitor of the organization, late payments, unethical behaviour, imposing low prices, constraint attempts, requesting too many concessions, etc.). Reasonable compromise makes a major contribution to the fulfilment of joint objectives, win-win negotiations and reciprocal advantages. 


\section{Approach of Customer Relationship}

\section{Dialogic communication}

Unlike traditional/transactional marketing, relational marketing focuses on frequent and intense communication with customers. CRM approaches have implemented systems through which representatives of organizations and customers are permanently in dialogue, bearing in mind that communication between partners is essential to the functioning of the relationship. The development of information and communication technologies has generated electronic CRM and social CRM implementation in many organizations, enabling one-to-one dialogue more frequently, both within B2B (business to business) and B2C (business to customer) relationships. Strategic CRM is able to integrate customer interactions across all communication channels, and front-office and back-office applications/business functions. CRM approaches frequently customize communications by tailoring the content and style of customer communications, usually for a particular segment or specific client, to ensure that the expectations of customers are met. Due to fierce competition, in the last few years a tendency for increased frequency of communications with customers in general (including advertising, brochures, and annual reports), and especially increased dialogic communications via the Internet, have been noticed, but also a decrease in face-to-face communications, which are often more efficient. For the sustainability of the companycustomer relationship, equilibrium between communication using social media and direct communication, face-to-face, is always necessary.

\section{Loyalty and commitment}

Without any doubt, CRM is the field in which company managers pay the greatest attention to loyalty. It was obvious more than a century ago that maintaining and increasing company sales depends largely on the organization's capacity to cultivate the customers' loyalty. Customer loyalty means the tendency of customers to continue to buy products and services from the same provider. Loyalty is generated mainly by customer satisfaction.

CRM, in order to obtain customer loyalty, develops loyalty segmentation and loyalty schemes. In loyalty segmentation, customers are evaluated and divided into three segments: very loyal, moderately loyal and disloyal. With these groups, based on analysis, any common characteristics are identified, so the product can be targeted at the prospectively loyal customers (Payne, 2005). Loyalty schemes through credits offered to customers can be used to guide customer acquisition, retention and development and may then serve as an exit barrier to customers. The credits accumulated reflect the value of the investment that a customer has made in the scheme and therefore in the relationship (Buttle, 2009). Customer loyalty has as a consequence consumer commitment, which, according to Walter, Mueller, Helfert, and Wilson 
(2002, p. 8), is "the intention of a customer to maintain a long-term relationship with a supplier". It is a measure of the future of the relationship. Concomitantly, the commitment of the company employees' managers specialized in customers is necessary, in order to maintain and develop long-term reciprocal advantageous relationships with the clients. This also requires a clear understanding of the potential benefits in terms of customer segment lifetime value (Payne, 2005).

While CRM approaches place in the foreground the increase of the loyalty of the clients, the loyalty of the company towards the clients is, not infrequently, neglected (e.g., promotional deals dedicated to new customers to the detriment of loyal customers, differentiated treatment of loyal clients), and some clients believe that loyalty within their relationship with the organization is not mutual, but is only one way from the client to the company. Besides these special loyalty actions, customer loyalty is positively influenced by joint objectives, win-win negotiation, reciprocal advantages and dialogic communication.

The CRM approaches favour to a high degree the commitment of customers and employees/managers in dealing with clients, but the unfair or wrong practices of some organizations negatively affect trust, which is an essential component of commitment, both of the clients to the company, and at the level of organization employees' loyalty.

\section{Collaboration and cooperation}

Any CRM - more or less sophisticated from a technological and/or social point of view - generates performances for company and customers only when it becomes operational. In practice, the main content of the CRM means effective and efficient collaborative and cooperative relationships between customers and company. In order to achieve this, everyone within the business must understand that they perform a role in serving customers (Payne, 2005) and that trust is vital and it should be present in each person and organization involved (Nguyen, 2012).

In practice, companies using CRM do not always succeed in developing relationships with customers based on mutual trust, which creates major difficulties regarding performant and sustainable collaboration and cooperation.

\section{Shared performances and rewards}

The main goal of CRM, as we have already emphasized in the first part of this chapter, is to increase the sales/buying of the company and its customers under conditions of reciprocal gains and satisfaction. This goal can only be achieved if each part contributes to the creation of enough value added that is able to satisfy reasonably the needs and expectations of the company and the customers. Successful CRM contains mechanisms capable of creating and sharing high performances for each 
party involved, to provide expected rewards to them. In business, CRM cannot always achieve such mechanisms. This explains why relatively many companies using CRM, after a certain period, do not continue their relationship with many customers. Shared performances mechanism, highly motivating the company and their customers to have sustainable relationships, represents a key element in CRM practices.

Evaluation of CRM from the point of view of the managerial synapse's main characteristics reveals its existence to different extents and in specific ways. CRM in the majority of its types is focused on the joint interests of the company and customers involved and is based, to a certain degree, on win-win negotiation, trust capital, reciprocal advantages, reasonable compromise, dialogic communication, loyalty and commitment, collaboration and cooperation, and shared performances and rewards. Of course, its intensity and approaches vary to a large degree from one type of CRM to another, and from one company to another.

CRM approaches from the last decade, based on relational marketing, long-term vision and relationships with customers, and especially on customization, using to a large extent specific software, including cloud based and social media, are closer to the valuable managerial synapse. CRM, by focusing on the customer, one of the most important stakeholders of the company, achieves one essential step ahead in managing much more performant company stakeholders.

Integration in CRM approaches of the new specific managerial synapse elements can contribute significantly to higher performances for both the company and their relevant customers.

\section{Perspectives and Ways to Develop CRM in Order to Become a Performant Managerial Synapse}

In this section, we deal only with the CRM that is focused on relevant stakeholders, which need and deserve a special mechanism in order to fully valorize their potential and to develop sustainable relationships with the company. Our proposal regarding the development of CRM in order to become a mature and performant managerial synapse is based mainly on three elements:

- features of the managerial synapse and mechanisms of its building and development;

- evaluation of CRM approaches and development in the last few years;

- main trends in the companies and business environment.

The starting point in the remodelling of CRM should be represented by the "Guide for performant managerial synapse construction, work and performance", presented in Chapter 6. All 14 phases incorporated in the 
guide should be adapted, of course, to the specificity of customers, sales and supply processes and taking into consideration the influences of the recent Covid-19 pandemic. In using this guide, we recommend paying special attention to the following set of essential elements:

\section{A Development of customer value chain}

The vision and the analysis should be based on the virtual value chain. As we have already outlined, in the present and near future the virtual value chain represents a business model capable of integrating the latest business informatics and social development. A virtual value chain focused on knowledge, the most important resource in the smart economy, and on networking, is an outstanding mechanism for connecting and valorizing the relevant external and internal company stakeholders. A specialized value chain for company customers - like the CRM value chain elaborated by Buttle (2009) - can be very helpful in this respect.

\section{B Determination of joint objectives}

Determination of the joint objectives for a company and relevant stakeholders is very important and frequently a difficult process in the construction of a manager-relevant stakeholders managerial synapse. For this type of managerial synapse, it is recommended to use the SMART model, which helps to determine for each component of the managerial synapse specific, measurable, agreed, realistic and time-bounded objectives. The other two models presented in Chapter 6 of the book - the "process centred objectives model" and the "contingency model of objectives" - are not recommended for this type of managerial synapse. The use of the SMART model should be based on win-win negotiation in order to establish joint objectives, highly motivational for the company and relevant customers, and to help in the development of a sustainable relationship. It is recommended that joint objectives are incorporated in a formal relational type of contract that creates a flexible framework designed with a view to achieving faster collaboration in strategic relationships over the long term (Frydlinger, Hart, \& Vitasek, 2019).

\section{Positive identity in work construction}

In recent years, many performant companies have focused on constructing a positive identity at work (see Section 7.6 in Chapter 7 of the book). A positive identity construction means that the person involved reconstruct themselves in their work field, resulting in strengthening themselves at work, increasing their capacity to generate and share knowledge, to take on new demands and challenges and to cope with stress, thereby enhancing performances regarding the size of sales, profit, market share, etc. According to the specialists Dutton, Roberts, and 


\section{2}

Approach of Customer Relationship

Bednar (2010), there are several pathways to construct a positive identity at work for the customer and the company. For company managers or specialists the following paths are suitable:

- path 2, which increases the trust and respect in the relationships between company manager/specialist and relevant customer;

- path 3, which makes a company representative and customer more attractive as a relational partner;

- path 7, which encourages the component of managerial synapse to develop new relationships between them.

Because it is possible for one person - company manager or customer to develop multiple identities, it is important to solve potential conflicts among these identities. Specialists (e.g., Jones \& Hynie, 2017) recommend several approaches, with reconciliation and realignment being suitable in the case of this managerial synapse.

Building a positive identity for the constituents of the customercompany manager synapse generates many advantages, including a positive company specialist attitude, task performance, citizenship behaviour and more effective task organization (Gallo, 2015).

\section{Use of a comprehensive set of motivations}

The functionality and performance of the managerial synapse with a relevant stakeholder depend largely on the degree of motivation of each individual involved. In Table 8.1, we present an indicative goals-motivation matrix, which might be used in order to increase the motivation of the relevant customers, and the company managers and specialists working with them. Elements incorporated in this matrix have been selected from the general indicative goals-motivation matrix presented in Section 6.9, Chapter 6, projected for all types of company-relevant stakeholders. Motivations, approaches and tools should be differentiated and personalized for each managerial synapse and for each manager, specialist and customer. In the differentiation and personalization of motivations it is recommended to take into consideration the main synapse joint objectives, the nature and complexity of the tasks to be accomplished by each person, the individual characteristics and motivational specificity of each managerial synapse component and the specific market trends (see Table 8.1).

\section{E Focus on the value creation stakeholder partnership with customers}

The management and promotion of a company manager/specialistrelevant customer managerial synapse should be based on several new economic and accounting approaches developed by specialists (Amit \& Zott, 2001; Andon, Baxter, \& Chua, 2015; Bosse, Phillips, \& Harrison, 


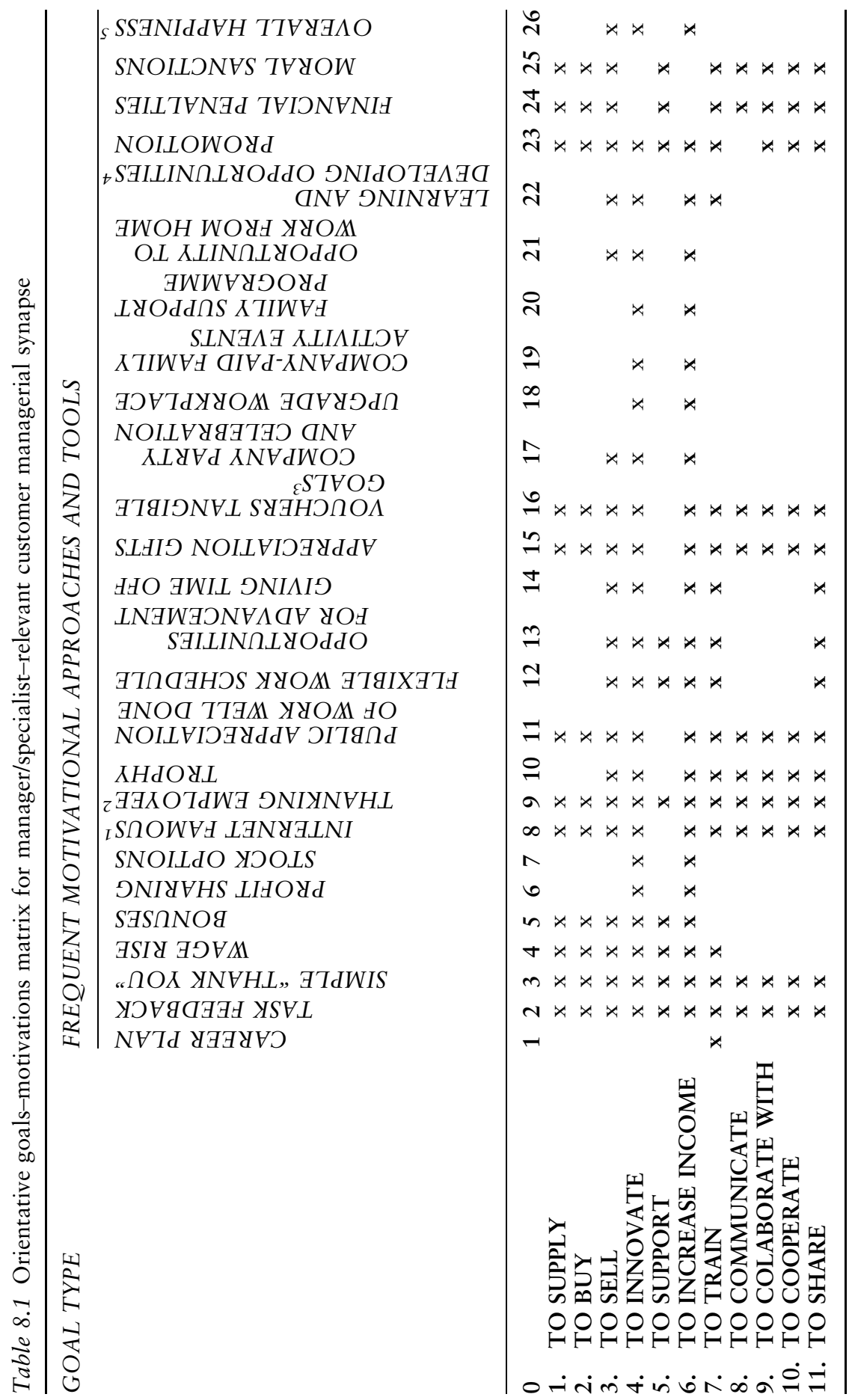




\section{Approach of Customer Relationship}

2009; Bowman \& Ambrosini, 2000; Brandenburger \& Stuart Jr., 1996; Brown \& Dillard, 2015; Crane, Graham, \& Himick, 2015; GarciaCastro \& Aguilera, 2015; Harrison \& van der Laan Smith, 2015; Lepak, Smith, \& Taylor, 2007; Mitchell, Van Buren, Greenwood, \& Freeman, 2015). These elements are at least the following:

- concept of total value created by the firm and all its stakeholders;

- model of value creation and appropriation with multiple stakeholders;

- value creation elasticity of stakeholder value appropriation;

- new branch of accounting focused on the relationship with stakeholders.

Using these new elements and other theoretical and pragmatic developments a new mechanism has been elaborated - value creation partnership - that helps to measure the contribution of the relevant customers and other stakeholders and to reflect it in accounting. This mechanism, which is in its "infancy", provides the necessary information and knowledge to the company management in order to determine the contribution of relevant customers to the creation of company's total value and to reward them accordingly.

A value creation stakeholder partnership is an expression of the managerial approach reflecting the newly empowered consumers in an evolving economy (Kihlström, 2019).

\section{F Networking the company manager/specialist-relevant customer managerial synapse}

A managerial synapse integrating the relevant customer generates better performances when it is networking with other managerial mechanisms. Three types of networking are mainly recommended:

a Integration of the managerial synapse in the individual supply chain management (Miri-Lavassani, Movahedi, \& Kumar, 2009) which is used most frequently in small companies. These companies usually represent about $90 \%$ of all companies in every country. There are individual supply chains specific to producers, suppliers and customers. By connecting the company manager/specialist-relevant customer managerial synapse with the individual chain of other customers the design, manufacture, distribution, marketing, sales and service for a product can be better correlated;

b Integration of the managerial synapse in the supply chain management that uses a supply chain collaboration platform (Sanders, 2017). This type of approach is usually used in corporations, large and medium-sized companies, valorizing to a high degree the collaborative 
platform and often generating a great and sustainable increase in sales, profit, market share, etc.

c Integration of the managerial synapse focused on the relevant customer in the company's relevant stakeholder management system. This system will be presented in Chapters 9, 10, and 11 of the book, and it is indicated there how the different company managerial synapses can be integrated within the system. This solution is able to ensure superior performances for a company and its relevant stakeholders.

\section{Classification of Manager-Relevant Customer Synapse}

In our opinion the six perspectives and approaches presented above should be the first to be taken into consideration by those who want to develop the CRM as a mature and performant managerial synapse. Each of them should be customized to the particular conditions of each company, its commercial managers and specialists and the relevant customers involved. In Table 8.2, we present the main types of this synapse and their main characteristics.

The information presented above can contribute to a better understanding of, and approach to, the manager/specialist-customer managerial synapse, enabling enhanced functionality and competitivity in organizations.

\section{Main Advantages and Limitations of the Customer-Centred Managerial Synapse}

The company manager/specialist-relevant consumer managerial synapse, compared with the classical company approach of customers with CRM, has many potential advantages:

- Development of a participative approach and team spirit between the company staff in the commercial field and the relevant customers;

- More fruitful win-win negotiation between company and relevant customers;

- Significant increase of the motivation degree of commercial company personnel and relevant stakeholders for higher efforts, productivity and other performances

- Increase of the joint decisions and actions between the managers and specialists on the one hand and relevant customer on the other;

- Contribution to the development of a positive identity at work both in the company commercial field and in the relevant customers' organization; 


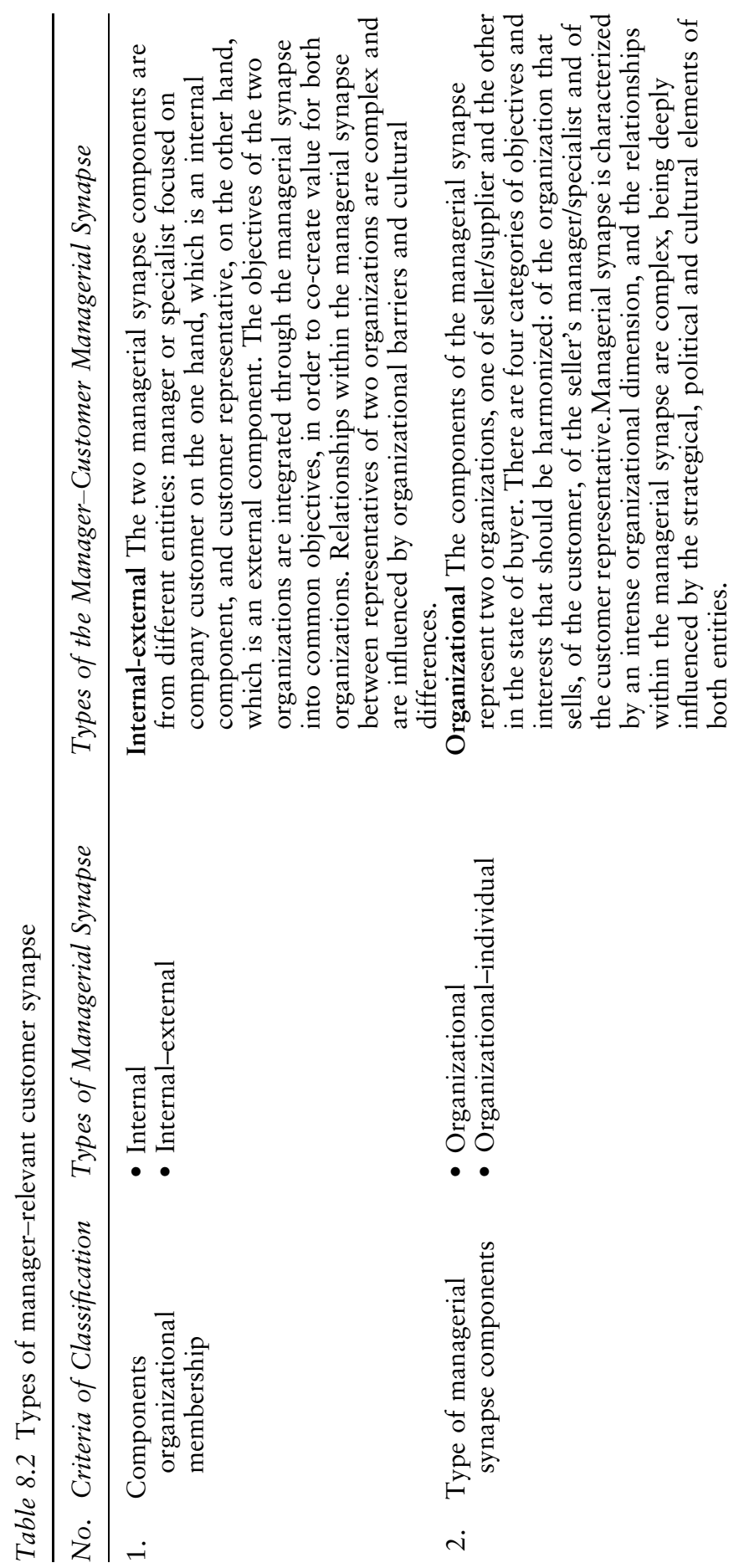




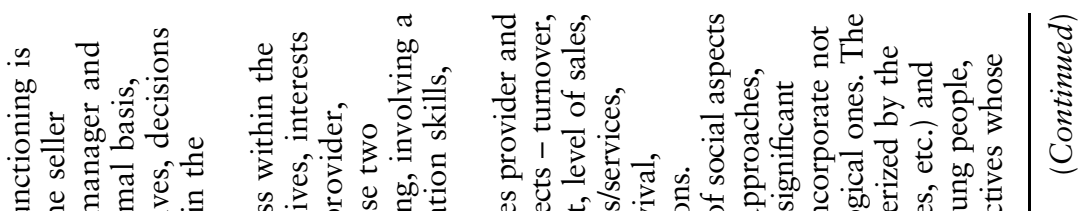

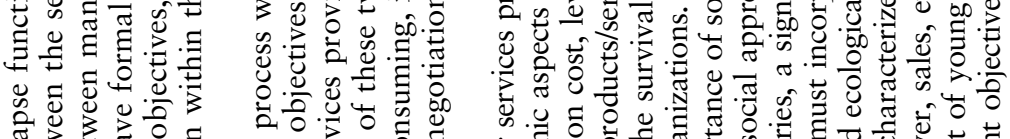

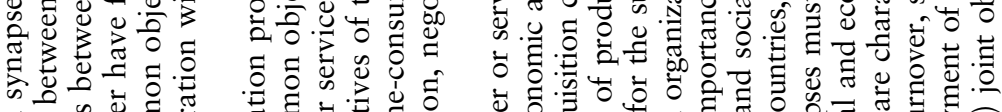

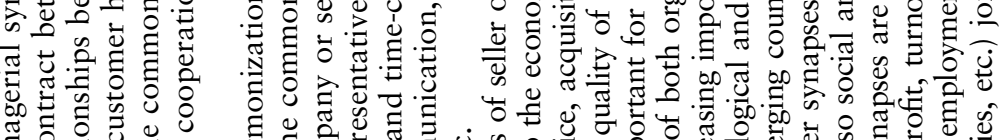

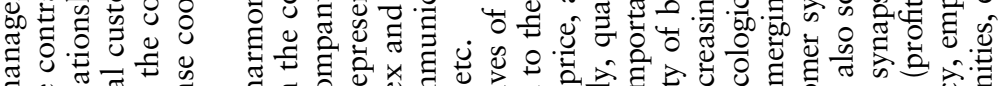

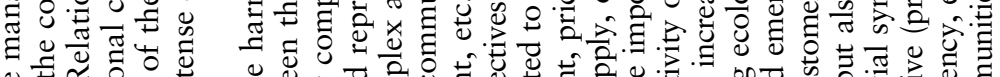

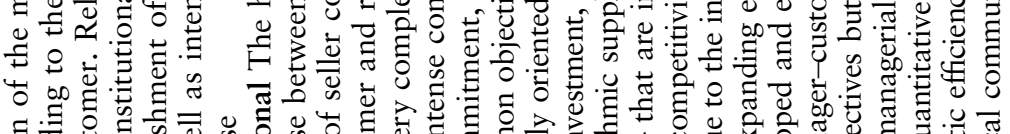

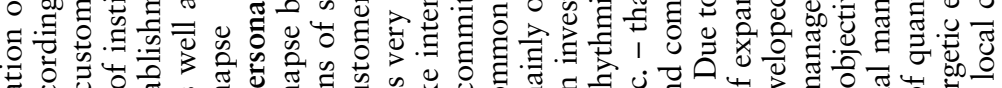

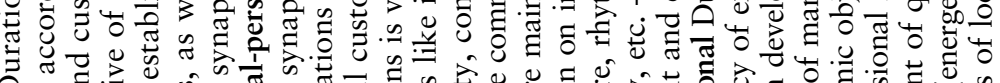

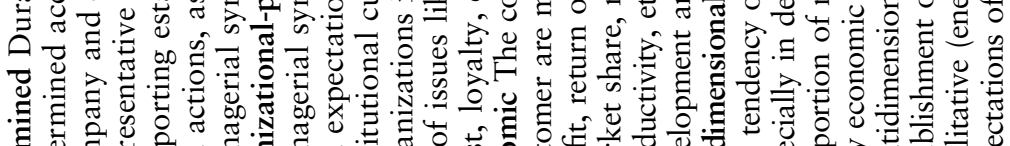

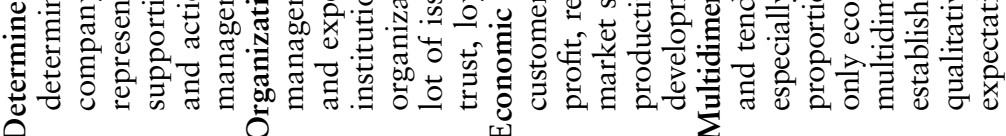

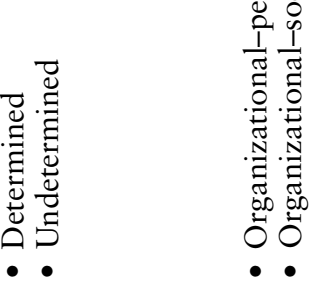

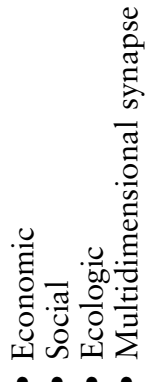

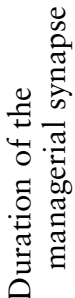
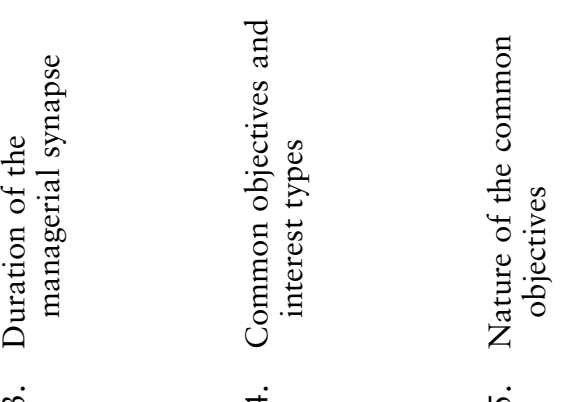

$\dot{n}$

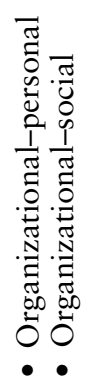




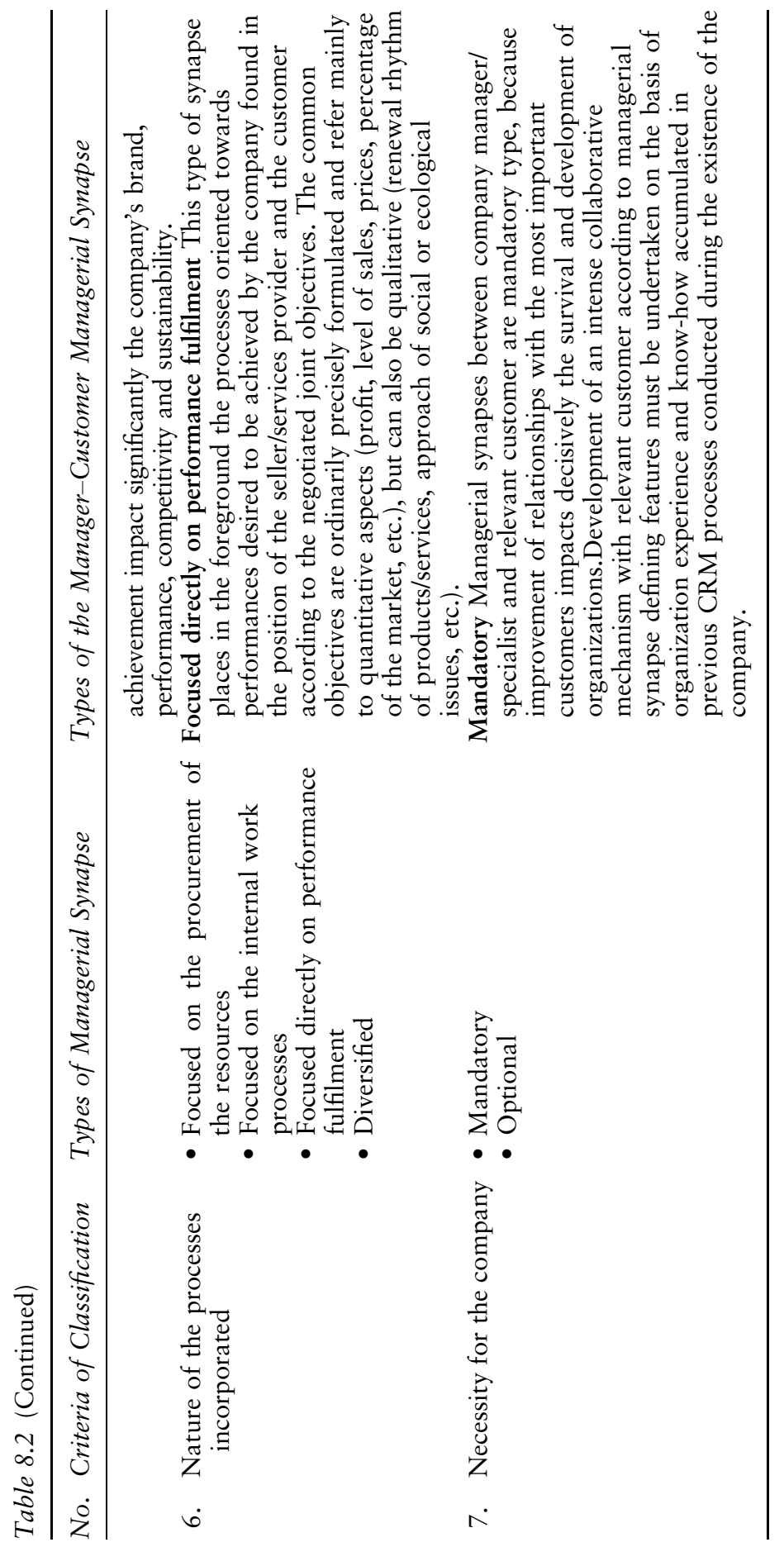


- Strengthening both categories of stakeholders - company employees and relevant customers at work;

- Intensification of the constructive and innovative behaviour of the commercial company managers and specialists and, respectively, relevant customers;

- Increase of the information, knowledge, deposit and transport facilities, etc. sharing between company commercial staff and the relevant customers;

- Increased capacity of the company and relevant customers to implement artificial intelligence, analytical metrics and other new digitalization gadgets for networking;

- Contribution to the development of an open and collaborative organizational culture at the level of company and relevant customers;

- Decrease of the conflict situations between the company's commercial representatives and relevant customers;

- Increase of company sales and relevant customers buying in the short, medium and long term;

- Increased engagement of relevant customers and company commercial managers and specialists in their organizations, in order to achieve joint objectives;

- Increase of sales and added value created by relevant customers and company employees in the commercial field;

- More sustainable relationship between company and relevant customers.

Concomitantly, this managerial synapse presents several specific limitations:

- Construction and development of managerial synapse incorporating relevant customers is very demanding in time and effort for those involved;

- Difficulty in reshaping the mentality and work approach of company managers and relevant customers according to the new managerial mechanism contained by managerial synapse;

- The relevant customer, either individual or organizational, has certain specific interests, different from joint interests, which do not always favour the managerial synapse construction, functioning and performance;

- One participant in the managerial synapse - the relevant customer is not a component of the company, having an organizational culture and work approach different from the company staff involved;

- Managers and specialists from a company that sells products and services do not often have enough knowledge and time in order to properly communicate, understand, negotiate and develop effective relationships with the relevant stakeholder;

- Difficulty in harmonizing the decisions, actions and behaviours of people who work in two organizations and have and other tasks to fulfil;

- Relevant customer is working in another location than the company, sometimes a long distance away, which can negatively influence the communication and cooperation with company representatives;

- The representative of the relevant customer, especially when they 
represent a large organization, depends from other manager in his company, which cannot be receptive enough to their integration in a managerial synapse with a representative of another company;

- Advancement of the relevant customer's career depends mainly on their own organization and much less on their work inside the managerial synapse with the representative from the sales company.

Finally, we consider it necessary to make the following three remarks:

a We emphasize the advantages of a managerial synapse incorporating relevant customers, because they represent arguments for using it. As we can see, there are 15 such arguments referring to the important elements for the company and relevant customers managerial synapse functioning and performance; these advantages continue to be valuable in the Covid-19 pandemic context.

b We emphasize the limitations faced by constructing and functioning the managerial synapse centred on relevant customers in order to facilitate their taking into consideration and avoiding major mistakes.

c Together, the advantages and the limitations provide a more analytic and realistic perception of this managerial synapse, enabling effective implementation in business.

The current evolution to the smart economy, digitalization, internationalization, artificial intelligence, metric analysis and other trends provides information, knowledge and tools capable of overcoming the limitations and simultaneously increasing and valorizing the specific advantages of this managerial synapse.

In the complex context generated by the Covid-19 pandemic in the CRM approach, and taking into consideration its advantages and limitations, the HEART framework, proposed recently by specialists, could be useful (Waldron \& Wetherbe, 2020).

\section{Notes}

1 Internet famous means: appreciations of employee on the company website, email with employee appreciation to everyone in the company, employee work business impact report on the company website, announcement with star of the month, etc.

2 Thanking employee by: praising employee, certificate of achievement, announcing an accomplishment at a company meeting, personal note of praise from manager, letter with thanks, handwritten appreciation note, etc.

3 Vouchers for: free or subsidized meals, fruits or drinks, sporting events, artistic events, paid group meals, wellness programmes, and other holiday vouchers.

4 Learning and development opportunities like: conference participation, training programmes, exhibition visits, mentoring, coaching, tutoring, counselling, etc. 
5 Overall happiness, see the analysis of Harrison and Wicks (2013).

\section{References}

Alt, R., \& Reinhold, O. (2019). Social customer relationship management: Fundamentals, applications, technologies. Gewerbestrasse, $\mathrm{CH}$ : Springer Nature. doi:10.1007/978-3-030-23343-3.

Amit, R., \& Zott, C. (2001). Value creation in e-business. Strategic Management Journal, 22(6-7), 493-520. doi:10.1002/smj.187.

Andon, P., Baxter, J., \& Chua, W. F. (2015). Accounting for stakeholders and making accounting useful. Journal of Management Studies, 52(7), 986-1002. doi:10.1111/joms.12142.

Askool, S., \& Nakata, K. (2011). A conceptual model for acceptance of social CRM systems based on a scoping study. AI \& Society, 26(3), 205-220. doi:10.1007/s00146-010-0311-5.

Bălan, C. (2007). Managementul relatiilor cu clientii: valente strategice, operationale si analitice. Revista de Marketing Online (Journal of Online Marketing), 1(3), 6-17.

Bergeron, B. (2004). Essentials of CRM: A guide to customer relationship management. New York: John Wiley \& Sons.

Blery, E. K., \& Michalakopoulos, M. G. (2006). An e-CRM application in the telecommunications sector: A case study from Greece. EuroMed Journal of Business, 1(2), 5-14. doi:10.1108/14502190610750135.

Bosse, D. A., Phillips, R. A., \& Harrison, J. S. (2009). Stakeholders, reciprocity, and firm performance. Strategic Management Journal, 30(4), 447-456. doi:10.1002/smj.743.

Boulding, W., Staelin, R., Ehret, M., \& Johnston, W. J. (2005). A customer relationship management roadmap: What is known, potential pitfalls, and where to go. Journal of Marketing, 69 (4), 155-166. doi:10.1509/jmkg.2005. 69.4.155.

Bowman, C., \& Ambrosini, V. (2000). Value creation versus value capture: Towards a coherent definition of value in strategy. British Journal of Management, 11(1), 1-15. doi:10.1111/1467-8551.00147.

Brandenburger, A. M., \& Stuart Jr., H. W. (1996). Value-based business strategy. Journal of Economics \& Management Strategy, 5(1), 5-24. doi:10.1111/j.1430-9134.1996.00005.x.

Brown, J., \& Dillard, J. (2015). Dialogic accountings for stakeholders: On opening up and closing down participatory governance. Journal of Management Studies, 52(7), 961-985. doi:10.1111/joms.12153.

Brunjes, B., \& Roderick, R. (2002). Customer relationship management: Why it does and does not work in South Africa. Paper presented at the IMM Marketing Educators Conference, South Africa.

Burnett, K. (2001). The handbook of key customer relationship management: The definitive guide to winning, managing and developing key account business. Upper Saddle River, NJ: Prentice Hall.

Buttle, F. (2001, February). The CRM value chain. Marketing Business, 


\section{Approach of Customer Relationship}

pp. 52-55. Retrieved from https://www.researchgate.net/publication/2283 96256_The_CRM_value_chain.

Buttle, F. A. (2004). Customer relationship management: Concepts and tools. Oxford, UK: Elsevier Butterworth-Heinemann.

Buttle, F. A. (2009). Customer relationship management: Concepts and technologies (2nd ed.). Oxford, UK: Elsevier Butterworth-Heinemann. Retrieved from https://knowledgestreams.files.wordpress.com/2013/07/francis_buttlecustomer_relationship_management_second_edition-butterworth-heinemann2008_2.pdf.

Chen, I. J., \& Popovich, K. (2003). Understanding customer relationship management (CRM): People, process and technology. Business Process Management Journal, 9(5), 672-688. doi:10.1108/14637150310496758.

Couldwell, C. (1999, February 18). Loyalty bonuses. Marketing Week, p. 14.

Crane, A., Graham, C., \& Himick, D. (2015). Financializing stakeholder claims. Journal of Management Studies, 52(7), 878-906. doi:10.1111/joms.12147.

CRM. (n.d.). Wikipedia. Retrieved from https://ro.wikipedia.org/wiki/CRM.

Drucker, P. F. (1954). The practice of management. New York: Harper.

Dutton, J. E., Roberts, L. M., \& Bednar, J. (2010). Pathways for positive identity construction at work: Four types of positive identity and the building of social resources. Academy of Management Review, 35(2), 265-293. Retrieved from https://www.researchgate.net/publication/228354753_Pathways_for_

Positive_Identity_Construction_at_Work_Four_Types_of_Positive_Identity_ and_the_Building_of_Social_Resources 10.5465/amr.35.2.zok265.

Dyché, J. (2002). The CRM handbook: A business guide to customer relationship management. Boston, MA: Addison-Wesley.

Ellatif, M. M. A. (2008). A cluster technique to evaluate effect of ECRM on customers' satisfaction of e-commerce websites. SSRN Electronic Journal. doi: $10.2139 /$ ssrn. 1128802 .

Faase, R., Helms, R., \& Spruit, M. (2011). Web 2.0 in the CRM domain: Defining social CRM. International Journal of Electronic Customer Relationship Management, 5(1), 1-22. doi:10.1504/IJECRM.2011.039797.

Farooqi, R., \& Dhusia, D. K. (2011). A comparative study of CRM and e-CRM technologies. Indian Journal of Computer Science and Engineering, 2(4), 624-627.

Frydlinger, D., Hart, O., \& Vitasek, K. (2019). A new approach to contracts. Harvard Business Review, 97(5), 116-124.

Gaetano, N. D. (2018, August 8). The evolution of CRM (and where it's going) in the future. Retrieved from https:/www.saleshacker.com/evolution-ofcustomer-relationship-management/.

Galbreath, J., and Rogers, T. (1999). Customer relationship leadership: A leadership and motivation model for the twenty-first century business. The TQM Magazine, 11(3), 161-171. doi:10.1108/09544789910262734.

Gallo, A. (2015). How to build a meaningful career. Harvard Business Review. Retrieved from https://hbr.org/2015/02/how-to-build-a-meaningful-career.

Garcia-Castro, R., \& Aguilera, R. V. (2015). Incremental value creation and appropriation in a world with multiple stakeholders. Strategic Management Journal, 36(1), 137-147. doi:10.1002/smj.2241.

Gartner. (n.d.). Gartner glossary. Retrieved from https://www.gartner.com/en/ information-technology/glossary/customer-relationship-management-crm. 
Glazer, R. (1997). Strategy and structure in information-intensive markets: The relationship between marketing and IT. Journal of Market Focused Management, 2 (1), 65-81. doi:10.1023/A:1009793717081.

Gneiser, M. S. (2010). Value-based CRM: The interaction of the triad of marketing, financial management, and IT. Business \& Information Systems Engineering, 2(2), 95-103. doi:10.1007/s12599-010-0095-7.

Greenberg, P. (2009). CRM at the speed of light: Social CRM strategies, tools and techniques for engaging customers. New York: McGraw-Hill.

Hammer, M., \& Champy, J. (1993). Reengineering the corporation: A manifesto for business revolution. New York: Harper Business.

Harrigan, P., Ramsey, E., \& Ibbotson, P. (2012). Exploring and explaining SME marketing: Investigating e-CRM using a mixed methods approach. Journal of Strategic Marketing, 20(2), 127-163. doi:10.1080/0965254X.2011. 606911.

Harrison, J. S., \& van der Laan Smith, J. (2015). Responsible accounting for stakeholders. Journal of Management Studies, 52(7), 935-960. doi:10.1111/ joms.12141.

Harrison, J. S., \& Wicks, A. C. (2013). Stakeholder theory, value and firm performance. Business Ethics Quarterly, 23(1), 97-124. doi:10.5840/beq2 0132314.

Hobby, J. (1999). Looking after the one who matters. Accountancy Age (October 28), pp. 28-30.

Jha, L. (2008). Customer relationship management: A strategic approach. New Delhi, India: Global India Publications.

Jones, J. M., \& Hynie, M. (2017). Similarly torn, differentially shorn? The experience and management of conflict between multiple roles, relationships, and social categories. Frontiers in Psychology, 8, 1732. doi:10.3389/fpsyg.201 7.01732 .

Kale, S. (2004). CRM failure and the seven deadly sins. Marketing Management, $13(5), 42-46$.

Karimi J., Somers T. M., \& Gupta Y. P. (2001). Impact of information technology management practices on customer service. Journal of Management Information Systems, 17(4), 125-158. doi:10.1080/07421222.2001.11045661.

Khasenova, D. (2017). Development of a software module for order status management at an event management company. Retrieved from https:/ bibliotecadigital.ipb.pt/bitstream/10198/14663/1/Dinara\%20Khasenova.pdf.

Kihlström, G. (2019). The agile consumer: Navigating the empowered economy and the future of customer experience. Arlington, VA: Agile Word.

Kotler, P. (1992a). It's time for total marketing. Business Week Advance Briefs, 2, 1-21.

Kotler, P. (1992b). Marketing's new paradigms: What's really happening out there. Planning Review, 20(5), 50-52. doi:10.1108/eb054382.

Kotorov, R. P. (2002). Ubiquitous organization: Organizational design for eCRM. Business Process Management Journal, 8(3), 218-232. doi:10.1108/14 637150210428934.

Kumar, V., \& Reinartz, W. (2018). Customer relationship management: Concept, strategy, and tools (3rd ed.). Berlin, DE: Springer-Verlag. 


\section{Approach of Customer Relationship}

Law, M., Wong, Y. H., \& Lau, T. (2005). The role of trust in customer relationship management: An example to financial services industry. Asia Pacific Management Review, 10(4), 267-274.

Lepak, D. P., Smith. K. G., \& Taylor, M. S. (2007). Value creation and value capture: A multilevel perspective. Academy of Management Review, 32(1), 180-194. doi:10.5465/amr.2007.23464011.

McKean, J. (2003). Customers are people... The human touch. Chichester, UK: John Wiley \& Sons.

Miri-Lavassani., K., Movahedi, B., \& Kumar, V. (2009). Transition to B2B e-marketplace enabled supply chain: Readiness assessment and success factors. The International Journal of Technology, Knowledge, and Society, 5(3), 75-88. doi:10.18848/1832-3669/CGP/v05i03/55999.

Mitchell, R. K., Van Buren, H. J., Greenwood, M., \& Freeman, R. E. (2015). Stakeholder inclusion and accounting for stakeholders. Journal of Management Studies, 52(7), 851-877. doi:10.1111/joms.12151.

Nguyen, B. (2012). The dark side of customer relationship management: Exploring the underlying reasons for pitfalls, exploitation and unfairness. Journal of Database Marketing \& Customer Strategy Management, 19, 56-70. doi:10.1057/dbm.2012.5.

Nguyen, B., Simkin, L., \& Canhoto, A. I. (2015). Introduction. In B. Nguyen, L. Simkin, \& A. I. Canhoto (Eds.), The dark side of CRM: Customers, relationships and management (pp. 1-19) London, UK: Routledge. doi:10.4324/ 9781315753737.

Pan, S. L., \& Lee J.-N. (2003). Using e-CRM for a unified view of the customer. Communications of the ACM, 46(4), 95-99. doi:10.1145/641205. 641212.

Parvatiyar, A., \& Sheth, J. N. (2001a). Conceptual framework of customer relationship management. In J. N. Sheth, A. Parvatiyar, \& G. Shainesh (Eds.), Customer relationship management: Emerging concepts, tools and applications (pp. 3-25). New Delhi, India: Tata/McGraw-Hill.

Parvatiyar, A., \& Sheth, J. N. (2001b). Customer relationship management: Emerging practice, process, and discipline. Journal of Economic and Social Research, 3(2), 1-34.

Payne, A. (2005). Handbook of CRM: Achieving excellence in customer management. Oxford, UK: Butterworth-Heinemann and Elsevier. Retrieved from https://repository.dinus.ac.id/docs/ajar/Handbook_of_CRM.pdf.

Payne, A., \& Frow, P. (2005). A strategic framework for customer relationship management. Journal of Marketing, 69(4), 167-176. doi:10.1509/jmkg.2005. 69.4.167.

Peppers, D., \& Rogers, M. (1993). The one to one future: Building relationships one customer at a time. New York: Currency Doubleday.

Peppers, D., \& Rogers, M. (1996). The one-to-one future: Building business relationships one customer at a time. London: Piatkus.

Peppers, D., \& Rogers, M. (2004). Managing customer relationships: A strategic framework. Hoboken, NJ: John Wiley \& Sons.

Peppers, D., Rogers, M., \& Dorf, B. (1993). Is your company ready for one-toone marketing? Harvard Business Review, 77(1), 151-160. 
Polonsky, M. J., \& Wood, G. (2001). Can the overcommercialization of causerelated marketing harm society? Journal of Macromarketing, 21(1), 8-22. doi:10.1177/0276146701211002.

Reinartz, W., Krafft, M., \& Hoyer, Wayne D. (2004). The customer relationship management process: Its measurement and impact on performance. Journal of Marketing Research, 41(3), 293-305. doi:10.1509/jmkr.41.3.293.35991.

Reinhold, O., \& Alt, R. (2011). Analytical social CRM: Concept and tool support. 24th Bled eConference eFuture: Creating Solutions for the Individual, Organisations and Society, pp. 226-241.

Reiny, I., \& Buttle, F. A. (2006). Strategic, operational, and analytical customer relationship management: Attributes and measures. Journal of Relationship Marketing, 5(4), 23-42. doi:10.1300/J366v05n04_03.

Sanders, N. R. (2017). Supply chain management: A global perspective (2nd ed.). Hoboken, NJ: John Wiley \& Sons.

Santos, J. D., \& Castelo, J. P. (2018). The six dimensions of adoption of a CRM strategy. In I. Lee (Ed.), Diverse methods in customer relationship marketing and management (pp. 17-43). Hershey, PA: IGI Global.

Stone, M., \& Woodcock, N. (2001). Defining CRM and assessing its quality. In B. Foss \& M. Stone (Eds.), Successful customer relationship marketing (pp. 3-20). London, UK: Kogan.

Subhasish, D. (2007). Customer relationship management. New Delhi, India: Excel Books.

Swift, R. S. (2000). Accelerating customer relationships: Using CRM and relationship technologies. Upper Saddle River, NJ: Prentice Hall.

Tohidi, H., \& Jabbari, M. M. (2012). CRM as a marketing attitude based on customer's information. Procedia Technology, 1, 565-569. doi:10.1016/ j.protcy.2012.02.123.

Trainor, K. J., Andzulis, J., Rapp, A., \& Agnihotri, R. (2014). Social media technology usage and customer relationship performance: A capabilities-based examination of social CRM. Journal of Business Research, 67(6), 1201-1208. doi:10.1016/j.jbusres.2013.05.002.

Waldron, T., \& Wetherbe, J. (2020). Ensure that your customer relationships outlast coronavirus. Harvard Business Review. Retrieved from https:/hbr.org/ 2020/04/ensure-that-your-customer-relationships-outlast-coronavirus.

Walter, A., Mueller, T. A., Helfert, G., \& Wilson, D. T. (2002). Delivering relationship value: Key determinant for customers' commitment. ISBM Report 8-2002. Retrieved from http://citeseerx.ist.psu.edu/viewdoc/download?doi= 10.1.1.202.2179\&rep=rep1\&type=pdf. 